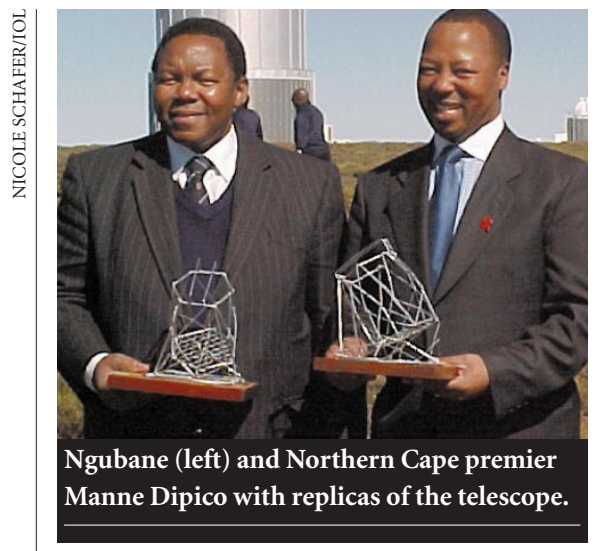

\section{Construction starts on largest telescope in the south}

\section{Michael Cherry, Cape Town}

Last Friday, work began outside the town of Sutherland, about 400 kilometres north-east of Cape Town, on building the largest telescope in the southern hemisphere.

The Southern African Large Telescope (SALT), due to be completed by the end of 2004, is similar in design to the HobbyEberly Telescope at Fort Davis in Texas, and will give astronomers an equivalent facility for the southern hemisphere.

SALT can access $70 \%$ of the sky observable at Sutherland, and will gather 20 times more light than any other African telescope. This allows observation of many important objects from the southern hemisphere, such as the centre of the Milky Way and the two nearest galaxies, the Magellanic Clouds.

The cost of construction and operation for the first ten years will be around R200 million (US\$30 million), a target that project scientist David Buckley says is just short of being met. Of this, $38 \%$ will come from the South African government, through the National Research Foundation.

The rest of the money is coming from universities in the United States, New Zealand and Germany, and from the Polish Academy of Sciences, which will receive a pro rata allocation of viewing time. Latest to join has been a consortium of UK institutions.

"The telescope will provide a focus for the development of basic sciences on the African continent," said Ben Ngubane, minister of arts, culture, science and technology at the opening ceremony.

A novel aspect of the project is a collateral benefits plan, which aims to ensure that SALT benefits South African society. For example, as many components as possible will be made locally.

\title{
Japan's desire to lead in IT fuels latest budget requests
}

\section{David Cyranoski, Tokyo}

Information technology (IT) fever has hit Japan's ministerial budget requests for next year, which were finalized last week. The government's mood was reflected in a promise by prime minister Yoshiro Mori's IT strategy panel that Japan will overtake the United States in IT in five years.

The ministries have responded accordingly. Increased funding is also slated for new programmes in nanotechnology, immunology and bioinformatics (see table). Butbrain, nuclear and space research all face decreased budgets within the Science and Technology Agency (STA).

An estimated $¥ 1$ trillion (US $\$ 9.4$ million) will be earmarked for IT in the new budget, which is likely to be formally approved, after slight modification by the government, later this year. It includes $¥ 364$ billion for the new National Land and Transportation Ministry and covers items such as the National Police Agency's cyberterrorism policy.

The IT budgets of the Ministry of International Trade and Industry (MITI) and the STA would both increase significantly (see table). But there has been criticism of the illdefined goals for the extra IT spending, especially the lack of a clear description of how the new public money will correlate with private initiatives.

The Mori panel's statement will do little more than temporarily "cheer up" the research and business community, says one senior researcher, who compares it to last year's "ridiculous" promise by the Japanese

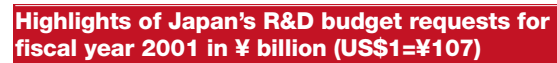

fiscal year 2001 in $¥$ billion (US\$1=¥107) 2001 request \% change

Ministry of International Trade and Industry (MITI)

\begin{tabular}{|c|c|c|}
\hline Total R\&D request & 587.9 & 11.2 \\
\hline Information technology & 52.6 & 190 \\
\hline $\begin{array}{l}\text { Materials Nanotechnology } \\
\text { Program }\end{array}$ & 5.0 & New \\
\hline $\begin{array}{l}\text { Medical innovation based } \\
\text { on genomic analysis } \\
\text { Protein Functional Analysis } \\
\text { Bioinformatics }\end{array}$ & $\begin{array}{r}16.3 \\
5.0 \\
5.0\end{array}$ & $\begin{array}{r}63 \\
270 \\
107\end{array}$ \\
\hline
\end{tabular}

Science and Technology Agency (STA)

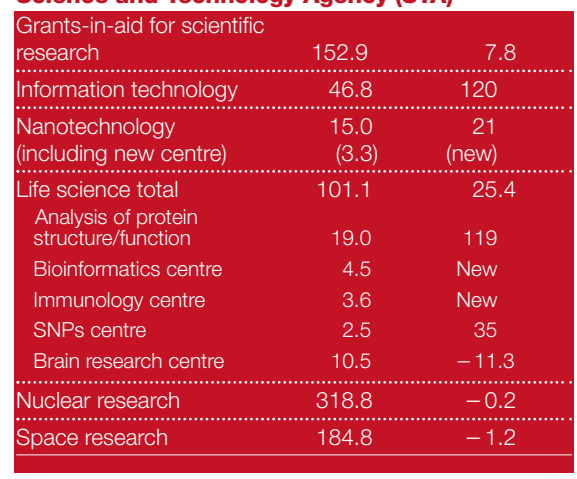

^ 2000 Macmillan Magazines Ltd government to spur the creation of 1,000 Japanese biotech start-up companies by 2010 .

But the budget requests also include some IT-related projects based firmly in areas of Japanese strength. Planners for the STA's Nanomaterial Research Center, for example, are promoting nanoscience as the key to Japan's 'IT revolution'.

A proposed budget of $¥ 3.3$ billion a year for five years for this area will go towards facilities in Tsukuba and for gathering researchers across Japan to work on a broad range of 'nanoprojects'. Having a centre around which networks can form is a top priority for building on research that is already strong in Japan, says the centre's Tomoji Kawai.

The MITI's Correlated Electron Research Center (CERC), a proposed eight-year, \$10 million a year project, also builds on Japanese strengths. The centre, growing out of the spin electronics division of the Joint Research Center for Atom Technology (JRCAT), will be in Tsukuba, and will continue the JRCAT's policy of encouraging industrial collaboration.

Yoshinori Tokura of Tokyo University, one of those behind CERC's creation, welcomes any boost IT might give his project. But he admits that his research - focused on organic or oxide-correlated electron systems — is far from ready for application.

The STA's Nanomaterial Research Center is a response to the US National Nanotechnology Initiative, announced in January, and consists of a \$5 billion budget (an 83\% increase) for nanotechnology (see Nature 405, 730-732; 2000). This initiative has challenged Japan to improve the organization of its research strengths to compete globally.

A MITI official says the US initiative, and visits by US government officials to Japan's nanotech research and development sites, appears to confirm that Japan is far ahead in many fields, stimulating a desire to stay on top, and leading to this year's budget requests.

Another field in which Japanese research is strong, but fragmented, is immunology. The STA has requested $¥ 3.6$ billion of renewable five-year funding for a centre, to be located in Tsukuba. This is partly intended to be a rallying point for a research community that some feel has not received the funding its status deserves. But planners also hope it will stimulate interaction between immunology researchers, hospitals and universities.

Bioinformatics will gain a new centre that aims to become Japan's version of the US National Center for Biotechnology Information. And proteomics will get a big increase for its nuclear magnetic resonance centre, which plans to characterize the structure and function of 3,000 proteins in the next five years. 